\title{
OSTEOARTHRITIS OF THE HIP JOINT; TO COMPARE THE OUTCOMES OF TOTAL HIP ARTHROPLASTY WITH HIP RESURFACING PROCEDURES IN PATIENTS, AT A TERTIARY CARE HOSPITAL IN KARACHI, PAKISTAN
}

Faisal Abdul Jabbar', Rehana Ali Shah ${ }^{2}$

1. Post Graduate FCPS Part II Trainee, Department of Orthopedics, Abbasi Shaheed Hospital, Karachi. 2. MBBS, FRCS

Professor and Head Department Orthopedics, Abbasi Shaheed Hospital, Karachi.

\section{Correspondence Address:}

Dr. Faisal Abdul Jabbar

Address: B-69, Block-3,

Gulshan-e-lqbal,

Karachi-75300, Pakistan.

drfaisaljabbar1@gmail.com

Article received on: 19/04/2017

Accepted for publication: $15 / 07 / 2017$

Received after proof reading: 03/11/2017
ABSTRACT... Objectives: The aim of our study is to determine the surgical outcome and rates of complication in patients undergoing surgical treatment for osteoarthritis of the hip joint with total hip arthroplasty and compare it with hip resurfacing procedures. Study Design: A prospective cohort study. Period: Five years duration from January 2011 to December 2016. Setting: Tertiary Care Centre in Karachi, Pakistan. Materials and methods: The study population consisted of $n=170$ patients $(n=110$ patients undergoing cementless THA and $n=60$ patients undergoing hip resurfacing procedures). The inclusion criteria was all the patients who came to our outpatient clinic, with unilateral or bilateral osteoarthritis (grade 3,4 ) of the hip joint requiring surgical treatment, were fit for surgery and gave informed consent to participate in the study. All the procedures were done by the same team of surgeons at the same institute in series under general anesthesia. Data was collected in a pre-designed proforma. Postoperatively the patients were restricted to a reduction of weight bearing by half for the first six weeks, and were involved in physiotherapy till discharge from the hospital. The patients from both groups received the same thromboembolic and infection prophylaxis. Data was analyzed using IBM SPSS version 22. Results: In our study we found that the rates of reoperation had statistically significant differences, being $n=5$ in THA group and $n=9$ in resurfacing group having a $p$ value of 0.019 . In the resurfacing group $n=4$ patients had fractures of the femoral neck. All the revision surgeries were undertaken utilizing the posterolateral approach, $n=2$ patients were revised utilizing cementless femoral stems while $n=2$ were revised utilizing cemented femoral stem, $n=5$ patients were revised to total hip arthroplasty procedure on account of aseptic loosening. No dislocations were observed after the revision surgical procedures. There was no statistically significant difference in the total rates of complications among the two groups, having a $p$ value of 0.44 . The pre-operative Harris hip scores were similar in the two groups having a $p$ value of 0.2 . Conclusion: According to the results of our study the outcome in the both the cementless total hip arthroplasty and hip resurfacing procedure are similar in terms of implant survival and clinical results however rate of complication is higher in the patients undergoing hip resurfacing technique and needed revision surgeries. The patients undergoing hip resurfacing had better mobility post operatively, and hence this consideration is to be made during patient selection, as hip resurfacing is preferred by younger patients due to its higher functional outcomes.

Key words: Total Hip Arthroplasty; Hip Resurfacing; Osteoarthritis; Developmental Dysplasia of Hip.

Article Citation: Jabbar FA, Shah RA. Osteoarthritis of the hip joint; To compare the outcomes of total hip arthroplasty with hip resurfacing procedures in patients, at a tertiary care hospital in Karachi, Pakistan. Professional Med J 2017;24(11):1669-1674. DOI:10.17957/TPMJ/17.3990

\section{INTRODUCTION}

Osteoarthritis is the scourge of modern medicine, it usually affects the large joints of the body, and cause non inflammatory damage to the cartilage and bone. In patients who have hip arthritis the final treatment modality upon failure of conservative methods is surgical intervention either with total hip arthroplasty (THA) or resurfacing, but this method of treatment has its fair share of drawbacks, such as loss of bone, osteolysis (wear related) and aseptic loosening. ${ }^{1,2,3}$ despite the drawbacks cementless total hip arthroplasty and resurfacing of the hip joint remain popular modes of treatment among the orthopedic surgeons. ${ }^{4}$ Middle aged patients with osteoarthritis of the hip have shown good outcome with press fit and 
cementless femoral stems. ${ }^{3}$ Fiber metal taper stems have displayed satisfactory outcomes in cementless total hip arthroplasty. ${ }^{5,6}$ Recently many patients have shown concerns regarding total hip arthroplasty due to its probable long term complications such as restriction of activity, dislocation, need for revision, and discrepancy in the leg length, hence these patients are opting for hip resurfacing (metal on metal hip resurfacing) technique as mode of treatment, as this method allows patients to return to their pre surgery level of activities, has lower rates of dislocations, conserves the bone stock and preserves the femoral anatomy. $7,8,9,10,11,12$ Early attempts at hip surfacing did not show promising results as it was riddled with complications (rapid wear and osteolysis). ${ }^{13,14}$ But the recent development in the implant technology with metal on metal (cobalt chromium heads of femur) bearing surfaces which have drastically decreased the wear of the implant, have spiked the interest of patients and surgeons alike. ${ }^{15}$ But this method still has its complications such as increased incidence of femoral neck fractures, metal ion generation, loosening and Osteonecrosis. ${ }^{16,17,18}$ Studies done to compare the two procedures have shown similar rates of complication and reoperations, but resurfacing is associated with better activity scores and range of motion of the hip joint, but data is still limited. ${ }^{19,20}$ The aim of this study is to compare the outcomes of total hip arthroplasty and resurfacing in patients have osteoarthritis of the hip joint, at Karachi, Pakistan, as data regarding the procedures is lacking from this part of the globe.

\section{MATERIALS AND METHODS}

The type of study is a prospective cohort study, conducted for a period of three years duration from January 2010 to December 2014, at a tertiary care centre in Karachi, Pakistan. The study population consisted of $n=170$ patients $(n=110$ patients undergoing cementless THA and $n=60$ patients undergoing hip resurfacing procedures). The study was approved by the hospital ethics committee and informed consent was taken from all the patients who participated in the study. The inclusion criteria was all the patients who came to our outpatient clinic, with unilateral or bilateral osteoarthritis (grade 3 and 4) of the hip joint requiring surgical treatment, were fit for surgery and gave informed consent to participate in the study. The exclusion criterion was all the patients who refused to participate in the study, were not fit for surgery and had significant co morbidities. The osteoarthritis of the hip was graded using the conventional radiographic grading system, having total 5 grades from 0 to 4 (grade 0 being normal, 1 being narrowed joint space and subtle osteophyte formation, 2 being definitive narrowing of the joint space, with osteophytes and some sclerosis, 3 being marked narrowing of the joint space, osteophytes, sclerosis and cyst formation with deformity in the femoral head and acetabulum, the last grade 4 is defined as gross narrowing of the joint space with large osteophytes, sclerosis, cysts and pronounced deformity of the femoral head and acetabulum, respectively) All the procedures were done by the same team of surgeons at the same institute in series under general anesthesia. Data was collected in a pre-designed proforma and included but was not limited to age, gender, type and duration of disease, complete history and clinical examination, mobility and range scores, levels of pain etc. In all the procedures of hip resurfacing a single type of prosthesis was utilized (made up of a high carbon cast with chrome cobalt cup). ${ }^{7,16,21,22}$ and the technique utilized was the same as described by Amstutz et al utilizing the posterior approach, the incision is made $8 \mathrm{~cm}$ from the greater trochanter and along the shaft, the muscles and fascia are separated, hip is dislocated and the capsule is excised, the femoral head is debulked, and is translocated superiorly and anteriorly to make room for the preparation of the acetabulum (implant placement) pin is inserted in the femur so that it makes an angle of 140 degrees with the shaft. The acetabular implant is placed after cleaning the reamed surfaces, fixation of the implant is ensured, the femoral head is prepared to be fixated in the acetabular implant, debris etc is removed. We used a cementless fixation of the femoral head with the acetabular implant in our study. ${ }^{21,22}$ Postoperatively the patients were restricted to a reduction of weight bearing by half for the first six weeks, and were involved in physiotherapy 
till discharge from the hospital. The total hip arthroplasty procedures were performed via the posterolateral approach and a fiber metal taper stem was utilized in the procedure. In the THA group patients were restricted to a $50 \%$ weight bearing (similar to the resurfacing group) for six weeks post operatively, after that they wereallowed full weight bearing. The patients from both groups received the same thromboembolic and infection prophylaxis. An international normalized ratio of 2.0 was maintained using the oral anticoagulant warfarin, which began on day the surgery and continued for three weeks duration afterwards. Cephalosporin and cefazolin were utilized for infection prophylaxis, the first dose administered prior to surgery and other remaining doses for a 24 hour period post operatively. Thromboembolic stockings were also utilized in patients to prevent thrombo embolism. At follow up all the patients were examined by the operating surgeon and data was collected in a pre-designed proforma which had variables regarding levels of pain, complications, functionality, activity and the Harris hip scores etc. ${ }^{23}$ Data was analyzed using SPSS version 22, unpaired Student $t$ test was utilized to analyze the two groups and paired student $t$ test was used to do statistical analysis within the group. Frequency and percentages was utilized for categorical variables. $P$ value of less than 0.05 was considered to be statistically significant.

\section{RESULTS}

In the hip resurfacing group there were $n=41$ males and $n=19$ females with a mean age of 49.5 years, the pathology in these patients was osteoarthritis in $n=50$ patients, developmental dysplasia in $n=6$ patients, for the rest of the demographics refer to Table-I. The patients were followed for a mean duration of 24.4 months respectively. In the total hip arthroplasty group there were $n=81$ males and $n=29$ females, having a mean age of 56.6 years, of which $n=91$ patients had osteoarthritis and $n=10$ patients had developmental dysplasia, the remaining patients had osteoarthritis secondary to Osteonecrosis and post traumatic osteoarthritis. For the rest of the demographic variables refer to Table-I. In our study we found that the rates of reoperation had statistically significant differences, being $n=5$ in THA group and $n=9$ in resurfacing group having a $p$ value of 0.019 respectively. In the resurfacing group $n=4$ patients had fractures of the femoral neck, these fractures occurred at 1 week, 7 months, 9 months and 14 months post operatively. All the revision surgeries were undertaken utilizing the posterolateral approach, $n=2$ patients were revised utilizing cementless femoral stems (press fit proximally coated) while $n=2$ were revised utilizing cemented femoral stem, $n=5$ patients were revised to total hip arthroplasty procedure on account of aseptic loosening.

\begin{tabular}{|l|c|c|c|}
\hline \multicolumn{1}{|c|}{ Characteristic } & Total Hip Arthroplasty, $\mathbf{n = 1 1 0}$ & Resurfacing, $\mathbf{n = 6 0}$ & P value \\
\hline Gender & $81(73.63 \%)$ & $41(68.33 \%)$ & \\
\hline Male & $29(26.36 \%)$ & $19(31.66 \%)$ & $<0.001$ \\
\hline Female & $56.6(34$ to 74$)$ & $49.5(30$ to 70$)$ & \\
\hline Age in years & & & \\
\hline Diagnosis & $91(82.72 \%)$ & $50(83.33 \%)$ & \\
\hline Osteoarthritis & $8(7.27 \%)$ & $2(3.33 \%)$ & \\
\hline Osteonecrosis & $10(9.09 \%)$ & $6(10 \%)$ & 0.019 \\
\hline Developmental dysplasia & $1(0.90 \%)$ & $2(3.33 \%)$ & 1.00 \\
\hline Post traumatic arthritis & 25 & 24.4 & 0.02 \\
\hline Mean time of follow up in months & $5(4.54 \%)$ & $9(15 \%)$ & 0.54 \\
\hline Need for revision surgery & & $4(6.66 \%)$ & 1.00 \\
\hline Complications & $7(6.36 \%)$ & $5(8.33 \%)$ & 0.44 \\
\hline Fracture & $0(0 \%)$ & $0(0 \%)$ & $1(1.66 \%)$ \\
\hline Aseptic loosening & $3(2.72 \%)$ & $10(16.66 \%)$ & \\
\hline Dislocation & $2(1.81 \%)$ & $12(10.90 \%)$ & \\
\hline Other & . & & \\
\hline Total & & & \\
\hline
\end{tabular}

Table-l. Patient characteristics and rates of complications of total hip arthroplasty and hip resurfacing groups. 


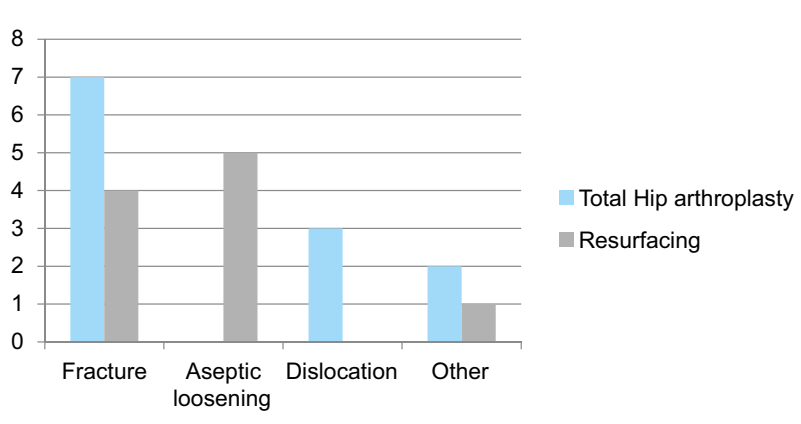

Figure-1. Rates of complications in the two groups (THA and resurfacing):

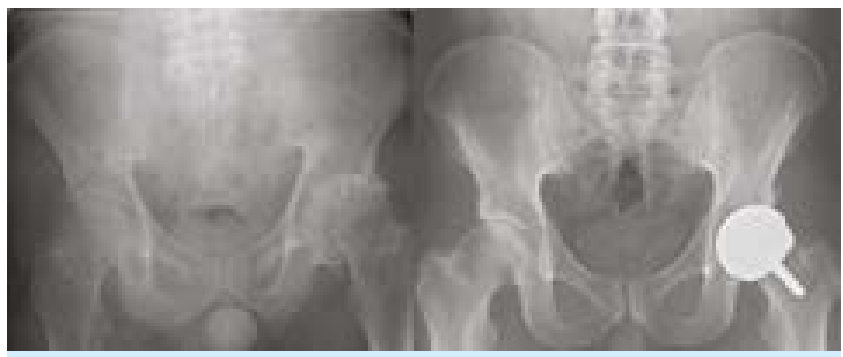

Figure-1,2. Pre operative and post operative radiographs of a patient undergoing hip resurfacing.

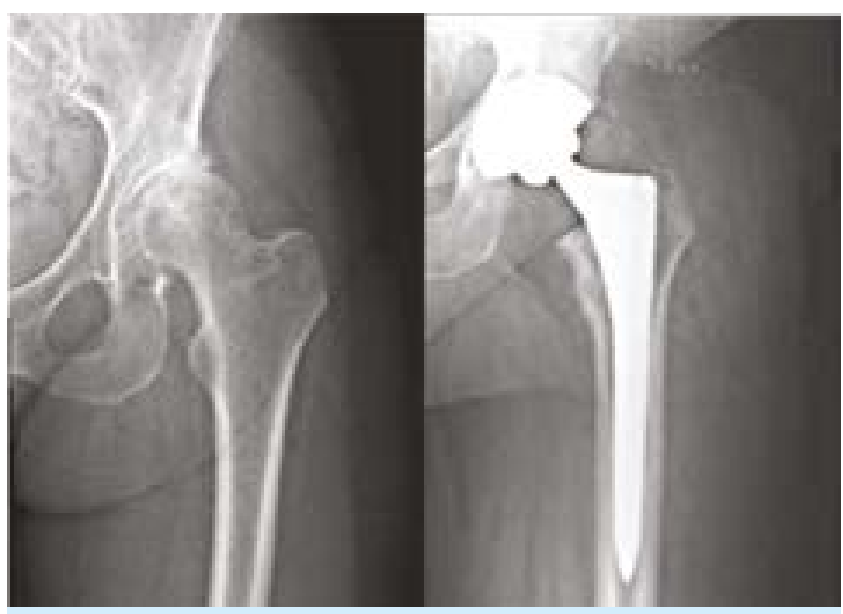

Figure-3,4. Pre operative and post operative radiographs of a patient undergoing Total hip arthroplasty.

No dislocations were observed after the revision surgical procedures. In the THA group from the patients who required revision surgery, $\mathrm{n}=3$ patients came with a history of fall and underwent open reduction and internal fixation (utilizing hook plate and cerclage wire), while $n=$ 2 suffered instability and had to undergo shell revision of the acetabulum. Further complications are listed in Table-I and Figure-1. There was no statistically significant difference in the total rates of complications among the two groups, having a $p$ value of $0.44 . n=7$ patients from the THA group suffered from incomplete fractures without extension beyond the lesser trochanter during the procedure, which were sustained during formation of the canal with broach in four cases. The rest of the fractures were observed upon impaction of the femoral stem, a stem of larger diameter $(16 \mathrm{~mm})$ was utilized for patients who had fractures. All the fractures were treated utilizing cerclage cables below the fracture level. No further complications were noted. Aseptic loosening was not observed in the THA group. The pre-operative Harris hip scores were similar in the two groups having a $p$ value of 0.2 respectively, the individual Harris hip scores were 58 in the THA group and 55.8 in the resurfacing group respectively. On the last follow up the Harris hip scores had shown significant improvement in both the groups, being 98.3 for the THA group and 96.1 for the resurfacing group having a $p$ value of $<0.005$ respectively. Figures-1,2,3 and 4 show the pre and post-operative radiographs of patients undergoing hip resurfacing and total hip arthroplasty.

\section{DISCUSSION}

In this study we compared the outcome of cementless total hip arthroplasty with metal on metal hip resurfacing techniques in patients with osteoarthritis of the hip joint, we compared the two procedures in terms of their post-operative complications, need for revision surgery and Harris hip scores.

We found that the initial rate of complication was similar in both the surgical techniques, but the rates of reoperation was higher in the patients belonging to the hip resurfacing group, which could be due to the fact that this is a relatively newer procedure and demands training measures to improve rates of outcome. ${ }^{24}$ This requirement of early need for revision has also been shown from the Scandinavian registry data ${ }^{25}$, the need for revision in total hip arthroplasty group was lower because of fewer post-operative complications. In our study the patients belonging to the total hip arthroplasty group were significantly older than the hip resurfacing group, having mean ages of 56.5 years and 49.5 years respectively having a 
$p$ value of less than 0.001 , which could be due to the fact that the higher mobility provided for by hip resurfacing is attractive to the younger patients. In the patients who had fractures after fall, their data was recorded for completion even though the cause of their fracture was not due to implant failure (greater trochanter fracture). While the dislocations and femoral head fractures were due to implant failure. The surgeons skill improves as he or she performs more surgeries of the similar kind, and Callaghan et al observed that radiographic results showed improvement from orthopedic surgeons initial 50 cases of cementless total hip arthroplasty towards the next 50 procedures. ${ }^{26}$ We did not analyze in our study markers of surgeons abilities such as operative time, blood loss during the procedure or length of stay. When it comes to the surgical complications we observed that patients in the THA group were more prone to developing intra operative fractures which occurred in $6.36 \%$ of the patients and were fixed while performing the index procedure, while in the hip resurfacing group the incidence of fracture was $6.66 \%$ which occurred after index procedure and warranted revision procedure. Studies suggest that with time as surgeons skills develop the incidence of complications is reduced. ${ }^{19,24} \mathrm{~A}$ large meta analysis comparing THA with resurfacing by Marshal DA et al showed that the need for revision surgery was earlier in the resurfacing group being a mean duration of 3 years versus 7.8 years with THA patients, and also found that dislocations were more common in the THA patients, which are similar to the results of our study. There were some limitations to our study which were, a small duration of follow up and small number of patient in the hip resurfacing group as compared to the total hip arthroplasty group, which can be fixed in future studies.

\section{CONCLUSION}

According to the results of our study the outcome in the both the cementless total hip arthroplasty and hip resurfacing procedure are similar in terms of implant survival and clinical results however rate of complication is higher in the patients undergoing hip resurfacing technique and needed revision surgeries. The patients undergoing hip resurfacing had better mobility post operatively, and hence this consideration is to be made during patient selection, as hip resurfacing is preferred by younger patients due to its higher functional outcomes.

Copyright(C) 15 July, 2017.

\section{REFERENCES}

1. Callaghan JJ, Bracha P, Liu SS, Piyaworakhun S, Goetz DD, Johnston RC. Survivorship of a Charnley total hip arthroplasty A concise follow-up, at a minimum of thirty-five years, of previous reports. $J$ Bone Joint Surg Am. 2009; 91:2617-2621.

2. lorio R, Robb WJ, Healy WL, et al. Orthopaedic surgeon workforce and volume assessment for total hip and knee replacement in the United States: preparing for an epidemic. J Bone Joint Surg Am. 2008; 90:15981605.

3. McLaughlin JR, Lee KR. Total hip arthroplasty with an uncemented tapered femoral component. J Bone Joint Surg Am. 2008; 90:1290-1296.

4. Dorr LD, Kane TJ 3rd, Conaty JP. Long-term results of cemented total hip arthroplasty in patients 45 years old or younger. A 16- year follow-up study. J Arthroplast. 1994; 9:453-456.

5. Akhavan S, Goldberg VM. Clinical outcome of a fibermetal taper stem: minimum 5-year followup. Clin Orthop Relat Res. 2007; 465:106-111.

6. Klein GR, Levine HB, Nafash SC, Lamothe HC, Hartzband MA. Total hip arthroplasty with a collarless, tapered, fiber metal proximally coated femoral stem: minimum 5-year follow-up. J Arthroplast. 2009; 24:579-585.

7. Amstutz HC, Grigoris P, Dorey FJ. Evolution and future of surface replacement of the hip. J Orthop Sci. 1998; 3:169-186.

8. Crawford JRPS, Wimhurst JA, Villar RN. Bone loss at hip resurfacing: a comparison with total hip arthroplasty. Hep Int. 2005; 15:195-198.

9. Girard J, Lavigne M, Vendittoli PA, Roy AG. Biomechanical reconstruction of the hip: a randomised study comparing total hip resurfacing and total hip arthroplasty. J Bone Joint Surg Br. 2006; 88:721-726.

10. Gore DR, Murray MP, Gardner GM, Sepic SB. Hip function after total vs. surface replacement. Acta Orthop Scand. 1985; 56:386- 390.

11. McMinn D, Treacy R, Lin K, Pynsent P. Metal on metal surface replacement of the hip. Experience of the McMinn prothesis. Clin Ortho Related Res. 1996; 
329:S89-98.

12. Vendittoli PA, Lavigne M, Girard J, Roy AG. A randomised study comparing resection of acetabular bone at resurfacing and total hip replacement. J Bone Joint Surg Br. 2006; 88:997-1002.

13. Charnley J. Arthroplasty of the hip. A new operation. Lancet. 1961; 1:1129-1132.

14. Head WC. Wagner surface replacement arthroplasty of the hip. Analysis of fourteen failures in forty-one hips. J Bone Joint Surg Am. 1981; 63:420-427.

15. Chan FW, Bobyn JD, Medley JB, Krygier JJ, The TM, Otto Aufranc Award. Wear and lubrication of metal-onmetal hip implants. Clin Ortho Relat Res. 1999; 369:1024.

16. Amstutz HC, Beaule PE, Dorey FJ, Le Duff MJ, Campbell PA, Gruen TA. Metal-on-metal hybrid surface arthroplasty: two to sixyear follow-up study. J Bone Joint Surg Am. 2004; 86-A:28-39.

17. Campbell P, Mirra J, Amstutz HC. Viability of femoral heads treated with resurfacing arthroplasty. J Arthroplast. 2000; 15:120-122.

18. Jacobs JJ, Skipor AK, Doorn PF, et al. Cobalt and chromium concentrations in patients with metal on metal total hip replacements. Clin Ortho Relat Res. 1996; 329:S256-263.

19. Nunley RM, Zhu J, Brooks PJ, et al. The learning curve for adopting hip resurfacing among hip specialists. Clin Orthop Relat Res. 2010; 468:382-391.

20. Vail TP, Mina CA, Yergler JD, Pietrobon R. Metal-onmetal hip resurfacing compares favorably with THA at 2 years followup. Clin Orthop Relat Res. 2006;
453:123-131.

21. Amstutz HCBP, Le Duff M. Hybrid metal on metal surface arthroplasty of the hip. Oper Tech Orthop. 2001; 11:253-262.

22. Amstutz HC, Beaule PE, Dorey FJ, Le Duff MJ, Campbell PA, Gruen TA. Metal-on-metal hybrid surface arthroplasty. Surgical technique. J Bone Joint Surg Am. 2006; 88(Suppl 1 Pt 2):234-249.

23. Harris WH. Traumatic arthritis of the hip after dislocation and acetabular fractures: treatment by mold arthroplasty. An end-result study using a new method of result evaluation. J Bone Joint Surg Am. 1969; 51:737-755.

24. Della Valle CJ, Nunley RM, Raterman SJ, Barrack RL. Initial American experience with hip resurfacing following FDA approval. Clin Orthop Relat Res. 2009; 467:72-78.

25. Johanson PE, Fenstad AM, Furnes $O$, et al. Inferior outcome after hip resurfacing arthroplasty than after conventional arthroplasty. Evidence from the Nordic Arthroplasty Register Association (NARA) database, 1995 to 2007. Acta Orthop. 2010; 81:535-541.

26. Callaghan JJ, Heekin RD, Savory CG, Dysart SH, Hopkinson WJ. Evaluation of the learning curve associated with uncemented primary porous-coated anatomic total hip arthroplasty. Clin Ortho Relat Res. 1992; 282:132-44.

27. Marshall DA, Pykerman K, Werle J, Lorenzetti D, Wasylak $T$, Noseworthy $T$ et al. Hip resurfacing versus total hip arthroplasty: a systematic review comparing standardized outcomes. Clin Orthop Relat Res. 2014 Jul; 472(7):2217-30.

\begin{tabular}{|c|c|c|c|}
\hline \multicolumn{2}{|c|}{ AUTHORSHIP AND CONTRIBUTION DECLARATION } \\
\hline Sr. \# & Author-s Full Name & \multicolumn{1}{c|}{ Contribution to the paper } & Author=s Signature \\
\hline 1 & Faisal Abdul Jabbar & $\begin{array}{l}\text { Corresponding author, write } \\
\text { up, data collection, data } \\
\text { analysis, literature review } \\
\text { Write up, data collection, } \\
\text { definition of intellectual } \\
\text { content, literature review final } \\
\text { draft, proof reading. }\end{array}$ \\
\hline 2 & Rehana Ali Shah & & \\
\hline
\end{tabular}

